\title{
Pheochromocytoma and Paraganglioma: From Treatment to Follow-up
}

\author{
(D) Nurcihan Aygun, (D) Mehmet Uludag \\ Department of General Surgery, University of Health Sciences Turkey, Sisli Hamidiye Etfal Teaching and Research Hospital, Istanbul, Turkey
}

\begin{abstract}
Pheochromocytomas (PCC) and paragangliomas (PGL) are rare neuroendocrine tumors arising from chromaffin cells in the adrenal medulla, sympathetic or parasympathetic ganglia. Currently, the only curative treatment option of pheochromocytomas/paraganglioma (PPGL) is surgical resection. Surgery aims to eliminate both risks of hypersecretion and tumor growth. The consequences of hypersecretion should be carefully controlled with medical therapy before and during the surgery. Postoperative major complications are hypotension and rebound hypoglycemia, and patients should be followed closely for 24-48 hours. The choice of surgical approach is determined based on multiple factors, including germline genetic test results, the size of the tumor, body mass index, surgeon's experience, and the likelihood of malignancy. Primary tumor resection does not completely eliminate the risk of tumor persistence and recurrence. Therefore, all patients with PPGL who are surgically treated should be followed for at least 10 years for recurrent disease and new tumor formation. Although surgical resection is the only curative treatment for PPGLs, surgical treatment is palliative except for resectable locoregional metastases in metastatic disease or for isolated distant metastases. The purpose of palliative treatment is to reduce hormone secretion and prevent metastasis-related complications in a critical anatomical location Combined and alfa; - and beta- adrenergic blockade is usually applied in patients with PPGL preoperatively. Some patients may present with pheochromocytoma multisystem crisis, which is a life-threatening condition that can involve cardiovascular, pulmonary, neurological, gastrointestinal, renal, hepatic and metabolic systems. Pheochromocytoma crisis may be spontaneous or may present with the tumor manipulation, trauma, corticosteroids, beta-blockers, anesthetic drugs, and the stimulation of nonadrenal surgical stress. These patients should be considered as medical emergencies rather than surgical emergencies. In this review, it was aimed to evaluate the pre-, per and post-operative management, curative and palliative surgical management, and postoperative outcomes and follow-up of the patients with PPGLs.
\end{abstract}

Keywords: Follow up; pheochromocytoma; paraganglioma; palliative; surgical; systemic treatment.

Please cite this article as "Aygun N, Uludag M. Pheochromocytoma and Paraganglioma: From Treatment to Follow-up. Med Bull Sisli Etfal Hosp 2020;54(4):391-398".

$\mathrm{P}$ heochromocytomas (PCC) and paragangliomas (PGL) are rare neuroendocrine tumors arising from chromaffin cells in the adrenal medulla, sympathetic or parasympathetic ganglia. ${ }^{[1,2]}$ Currently, the only curative treatment option of pheochromocytomas/paraganglioma (PPGL) is surgical resection. Surgery aims to eliminate both risks of hypersecretion and tumor growth. The consequences of hypersecretion should be carefully controlled with medical therapy before and during the surgery. The choice of surgical approach is determined based on multiple factors, including germline genetic test results, the size of the tumor, body mass index, surgeon's experience, and the like-

Address for correspondence: Nurcihan Aygun, MD. Saglik Bilimleri Universitesi, Sisli Hamidiye Etfal Tibbi Uygulama ve Arastirma Merkezi, Genel Cerrahi Anabilim Dali, Istanbul, Turkey

Phone: +90 5532779578 E-mail: nurcihanaygun@hotmail.com

Submitted Date: August 03, 2020 Accepted Date: August 25, 2020 Available Online Date: December 11, 2020

${ }^{\circ}$ Copyright 2020 by The Medical Bulletin of Sisli Etfal Hospital - Available online at www.sislietfaltip.org

OPEN ACCESS This is an open access article under the CC BY-NC license (http://creativecommons.org/licenses/by-nc/4.0/). 
lihood of malignancy. Primary tumor resection does not completely eliminate the risk of tumor persistence and recurrence. ${ }^{[1-4]}$ Therefore, all patients with PPGL who are surgically treated should be followed for at least 10 years for recurrent disease and new tumor formation..$^{[5]}$

In this review, it was aimed to evaluate the pre-, per- and post-operative management, curative and palliative surgical management, and postoperative outcomes and followup of the patients with PPGLs.

\section{Perioperative Treatment}

\section{Preoperative Treatment}

Preoperative blockade is recommended in functional PPGLs to prevent perioperative cardiovascular complications. ${ }^{[4]}$ There are no randomized controlled trials supporting the use of a-adrenergic blockade in preoperative patients. ${ }^{[6]}$ In a recent multicentric retrospective study, tumor-specific complications associated with hemodynamic instability were found to be higher in patients receiving preoperative a-blockers ( $5.9 \%$ vs. $0.9 \%$, respectively), and mortality rates were similar. Additional prospective randomized studies are needed to address which patients will benefit from a-blocker therapy ${ }^{[7]}$ Although the preoperative preparation of patients with PPGL using a-blocker has become highly dogmatic, it is recommended as guidelines or expert advice, and the a-receptor blockade is routine in the clinical practice of many centers. ${ }^{[4]}$

Combined $\alpha$ - and $\beta$ - adrenergic blockade is usually applied in patients with PPGL. An a-adrenergic blockade may be applied via non-selective or selective adrenergic receptor antagonists. Non-selective a-adrenergic blockade is started with an oral dose of $2 \times 10 \mathrm{mg}$ phenoxybenzamine and can be increased to a dose of $1 \mathrm{mg} / \mathrm{kg} /$ day, depending on the age of the patient, with blood pressure adjusted to the lower limit of normal limits. ${ }^{[4,8]}$ If the selective $a-1$ adrenergic blockade is to be performed, doxazosin can be started at a dose of $2 \mathrm{mg} /$ day and can be increased up to $32 \mathrm{mg} /$ day until the desired blood pressure is obtained. ${ }^{[4]}$ In the recent prospective randomized study, although phenoxybenzamine was more effective in preventing intraoperative hemodynamic instability than doxazosin, it was not been established whether this was related to better clinical outcomes. ${ }^{[9]}$ Patients who are administered adrenergic blockade should be accompanied by a high-dose sodium diet $(5000 \mathrm{mg} /$ day) and adequate daily fluid intake ( $2.5 \mathrm{~L} /$ day) to prevent severe hypotension after tumor removal. ${ }^{[8]}$ Another option is to administer 1-2 L intravenous saline $(0.9 \% \mathrm{NaCl})$ solution one day before the surgery. ${ }^{[6]}$ The aim should be to keep the blood pressure below $130 / 80 \mathrm{mmHg}$ while sitting and not lower than $80 / 45 \mathrm{mmHg}$ while stand- ing. The target in the heart rhythm is $60-70 \mathrm{bpm}$ while sitting and 70-80 bpm while standing. ${ }^{[10]}$ If the patient's blood pressure cannot be controlled with the a-adrenergic blockade, additional calcium channel blocker can be used. In addition, calcium channel blocker can be used alone in patients with normotensive or mild hypertension ${ }^{[6]}$ The tyrosine hydroxylase inhibitor metyrosine, which inhibits catecholamine synthesis, should be administered in patients who cannot tolerate a-blocker or in hypertension that cannot be controlled by a-blocker and/or calcium channel blocker ${ }^{[2]}$ However, recent data suggest that the use of metyrosine in combination with preoperative phenoxybenzamine may reduce intraoperative hemodynamic instability and postoperative cardiovascular problems. ${ }^{[11]}$ If the patient is at home preoperatively, they should be recommended to check and record blood pressure and pulse at least twice a day.

If the pulse is above $100 \mathrm{bpm} \mathrm{3-4}$ days after a-blockade is started, $\beta$ - adrenergic receptor blockade should be administered to control tachycardia. The use of beta-adrenergic receptor blockers without the initiation of an a-receptor blocker is not recommended due to the potential for hypertensive crisis with the unopposed stimulation of a-adrenergic receptors. Propranolol can be started up as $3 \times 20 \mathrm{mg} /$ day and can be increased up to $3 \times 40 \mathrm{mg} /$ day depending on heart rate. Or atenolol $25 \mathrm{mg} /$ day can be started and the dose can be increased to $50 \mathrm{mg} /$ day. Although there are no data regarding the optimal duration of preoperative treatment, blood pressure and heart rate can be normalized with 7-14 days of treatment. ${ }^{[4]}$ Tachycardia is less common in those who use selective a-blockers, but especially in patients who use phenoxybenzamine, additional $\beta$-adrenergic receptor blockade is often required for tachycardia control. Even if the patient does not have hypertension, blockade should be initiated with low-dose a-blocker. Phenoxybenzamine, $\beta$-blockers, calcium channel blockers, doxazosin can be used safely in pregnant women. ${ }^{[2]}$

\section{Pheochromocytoma Crisis}

Some patients may present with pheochromocytoma multisystem crisis. Although this condition is rare, it is a life-threatening condition that can involve cardiovascular, pulmonary, neurological, gastrointestinal, renal, hepatic and metabolic systems and cause different symptoms related to these systems and can be difficult to diagnose. ${ }^{[12]}$ The patient may present with hypertension or hypotension, hyperthermia, encephalopathy or multiorgan failure and it may be associated with high mortality ${ }^{[13,14]}$ Pheochromocytoma crisis may be spontaneous or may present with the tumor manipulation, trauma, corticosteroids, $\beta$-blockers, anesthetic drugs, and the stimulation of non-adrenal surgical stress. ${ }^{[4,12]}$ 
In these patients, immediate surgical intervention without stabilizing the patient is associated with high morbidity and mortality. These patients should be considered as medical emergencies rather than surgical emergencies. Many of these patients can be stabilized with a-blocker. However, such patients should be followed and stabilized with a multidisciplinary approach. ${ }^{[14]}$ Rarely, intra-aortic balloon pump (IABP) or extracorporeal membrane oxygenation (ECMO) may be required to treat severe cardiogenic shock, which can contribute significantly to treatment and increase survival. Tumors can be resected within 1-2 weeks in patients who generally recover with medical and intensive care support. However, in very severe cases, immediate surgery may rarely be required. ${ }^{[14-16]}$ In addition, immediate surgery may be required in case of tumor rupture or uncontrolled bleeding. ${ }^{[12]}$

\section{Intraoperative Treatment}

Communication and collaboration of the anesthesia and surgical team are important for the success of the operation. Before starting the surgery, a large vein or central venous catheter should be placed on the patient. Radial artery is cannulated for hemodynamic monitoring. Anesthesiologist should be prepared for the treatment of blood pressure changes. Esmolol is the most commonly used agent in intraoperative hypertension. Intravenous magnesium sulfate can be used in refractory hypertension. In surgery, blood pressure increase and arrhythmia can be seen with the manipulation of the tumor. In this case, the surgeon is warned by the anesthesiologist and the manipulation is stopped until the blood pressure decreases. If necessary, medication may be administered by the anesthesiologist to lower the blood pressure. Hypotension may occur after the tumor is removed. In this case, the patient is administered intravenous isotonic fluid $(0.9 \% \mathrm{NaCl})$. Bolus or infusion ephedrine or phenylephrine can be administered if needed. ${ }^{[6]}$

\section{Early Postoperative Follow-up and Treatment}

Postoperative major complications are hypotension and rebound hypoglycemia, and patients should be followed closely for 24-48 hours. ${ }^{[4]}$

The patient's blood pressure, pulse, urine output and blood sugar should be closely monitored. Acute postoperative hypotension is generally related to the sudden fall of the catecholamines in the circulation and the expansion of the intravascular space due to the residual alpha-blocking effect. Intravenous fluid resuscitation is required. Vasopressor (ephedrine, phenylephrine, norepinephrine) can be administered, if necessary. ${ }^{[6]}$ Reactive hypoglycemia may occur after PPGL resections, although not very often. High cat- echolamine levels suppress $\alpha$ and $\beta$ cells in the pancreas. Rebound insulinemia may occur after surgery. Associated hypoglycemia typically occurs in the first four hours postoperatively. The patient's glucose level should be checked every six hours. The patient is administered intravenous dextrose $5 \%$ until tolerating oral intake, especially in diabetic patients, insulin requirement should be adjusted postoperatively. ${ }^{[4,6]}$

\section{Surgical Treatment}

The main treatment of PPGL is surgery, and it offers the best chance for cure or remission. According to the patient's biochemical tests, genetic tests, anatomical and functional imaging results, the surgery is planned individually. ${ }^{[6]} \mathrm{Ad}-$ renal surgery can be performed with the laparoscopic or open technique. ${ }^{[17,18]}$ Both methods can be applied transabdominally or retroperitoneally. Laparoscopic surgery can be applied conventionally or robotically. ${ }^{[18]}$ The choice of surgery depends on the diameter and type of the lesion, the general characteristics of the patient, the surgeon's experience and preference. ${ }^{[17]}$ Laparoscopic adrenalectomy has become the gold standard treatment in the treatment of selected patients. ${ }^{[18]}$ Laparoscopic adrenalectomy should not be considered a contraindication even in patients with situs inversus. ${ }^{[19]}$ Laparoscopic adrenalectomy is a minimally invasive surgical procedure, and intraoperative blood loss, postoperative pain, length of hospital stay, total 30-day postoperative complications and mortality rates are lower than open interventions. ${ }^{[18]}$

The basic principles in adrenal surgery for PCC include early identification and ligation of the adrenal vein, minimal manipulation of the tumor to prevent tumor rupture or the release of catecholamines that may cause blood pressure fluctuations. ${ }^{[18,20]}$

Laparoscopic adrenalectomy is recommended for the treatment of many patients with PCC. ${ }^{[18]}$ While laparoscopic adrenalectomy is recommended in PCCs up to $6 \mathrm{~cm}$, open adrenalectomy is recommended to provide complete tumor resection, prevent tumor rupture and local recurrence in PCCs over $6 \mathrm{~cm}$. Open surgery is recommended in PGLs because they have a higher risk of malignancy, and the tumor is often located in difficult anatomical regions for laparoscopic resection. ${ }^{[4]}$ However, laparoscopic surgery can be performed in small non-invasive PGLs at appropriate localization that do not require adjacent organ resection. ${ }^{[4,17,21]}$

Larger tumors have a higher risk of both metastatic disease and tumor rupture. ${ }^{[22]}$ Tumor rupture of primary PCC during surgical resection may result in tumor spillage and peritoneal and retroperitoneal dissemination. This can result in even an apparently benign process to become peritoneal 
carcinomatosis and metastatic disease, which can potentially be fatal. Therefore, resection of the tumor completely and without rupture is very important for a good prognosis. In addition, in the case of tumor rupture, these patients must be carefully monitored because recurrence may occur after prolonged significant remission. ${ }^{[23]}$ Preoperative knowledge of the type of preoperative germline mutation in PPGL affects the type of surgical approach and the extension of adrenalectomy. ${ }^{[24]}$

Open adrenalectomy may be preferred in patients with SDHB, TMEM127 or FH germline mutations, as the risk of extra-adrenal disease, metastatic disease or recurrence risk is higher than in patients with NF1, RET or VHL germline mutations. ${ }^{[20,24]}$ Open surgery is preferred in patients with multifocal lesions where the laparoscopic approach is not possible. ${ }^{[6]}$ Rarely, en bloc resection may require resection with the surrounding organs; open surgery should be preferred in this case. ${ }^{[25]}$ In metastatic diseases, metastases occur primarily in lymph nodes; therefore, locoregional lymph node dissection should be performed together with primary tumor during laparotomy, in patients in whom lymph node metastasis is detected in preoperative imaging or during the intraoperative evaluation, or in patients with a high risk of lymph node metastasis, such as SDHB germline mutation. ${ }^{[6]}$ Surgery may be curative in cases with metastases to regional lymph nodes. ${ }^{[26]}$ Although PGLs are rarer than PCC, they are more likely to be malignant. Malignant PGLs often have a dense fibrous capsule and adhere to surrounding vascular structures, which can complicate complete resection. Preoperative preparation should be performed for possible vascular reconstructions with en bloc resection. ${ }^{[25]}$ Multiple primary PGLs are often indistinguishable clinically from metastases to aortocaval lymph nodes, and in these cases, regional lymph node dissection should be performed. ${ }^{[6]}$

Partial adrenalectomy or cortical-sparing adrenalectomy can be performed in some selected patients with PCC to maintain adrenocortical function, to avoid lifelong steroid replacement, which has a negative effect on the quality of life. ${ }^{[18]}$ Cortical-sparing surgery is preferred in patients with a high risk of bilateral disease and low probability of malignancy, such as MEN2 or VHL syndrome. Although the exact amount of adrenal gland remnant required is unknown, this approach has been shown to prevent postoperative adrenal insufficiency in up to $90 \%$ of patients. ${ }^{[20]}$

\section{Head and Neck Paragangliomas}

Head and neck PGLs are generally nonfunctional, and these are named according to the anatomical region they originate from, as carotid body PGL, jugulotympanic (middle ear) PGL, vagal PGL and laryngeal PGL. Carotid body
PGLs constitute more than half of the head and neck PGLs. Less than $5 \%$ of all head and neck PGLs metastasize and the rate of metastasis is lower in carotid PGLs. Hereditary head and neck PGLs can be multiple and occur in association with sympathetic PGLs. Apparently, germline mutation is less than $20 \%$ in patients with sporadic tumors and much higher in patients with family history. The most commonly noted is the SDHx mutations. PGLs associated with SDHB mutations have a high risk of metastasis. ${ }^{[27]}$ Traditionally, although first-line treatment of most of the carotid body PGLs is considered as surgical resection, recent evidence showing that many tumors have relatively low rates of malignancy increased interest in non-surgical treatments or follow-up. Surgical resection morbidity can be avoided by actively monitoring patients with the indolent disease, knowing the risk of metastasis, tumor biology, growth rate, tumor size, patient age, mutation status. ${ }^{[6]}$

Carotid body PGLs are often associated with germline mutations. SDHx mutations are the most common and are associated with paraganglioma syndromes from 1 to 4 (SDHD, SDHAF2, SDHC and SDHB mutations, respectively). While SDHB mutations cause more aggressive disease and metastasize more than SDHD mutations, SDHD mutations cause head and neck PGLs with higher rates and PCC with lower rates. ${ }^{[28]}$ Ellis et al. ${ }^{[28]}$ revealed that carotid body PGLs with SDHB mutation was associated with worse diseasefree survival after resection despite early intervention, and a more aggressive surgical approach is required in these patients. However, in the carotid body PGLs without SDHB mutation, they reported that if the lesion is asymptomatic, its diameter is less than $2 \mathrm{~cm}$ and not biochemically hormone-active, the follow-up option can be considered. ${ }^{[28]}$

In carotid body PGLs, the risk of stroke and cranial nerve injuries are significantly increased as the tumor relates to the surrounding vessels and the difficulty of resection increases (Shamblin classification type $3>$ type $2>$ type 1 ). Total stroke rate after carotid body $\mathrm{PGL}$ resection is $3.5 \%$, and cranial nerve injury rate persisting for more than 30 days is $11.5 \%$. Neck haematoma rate requiring reexploration is $5.2 \%$, and preoperative embolization does not decrease the rate of haematoma requiring reexploration. ${ }^{[29]}$ In a patient presenting with multifocal disease, including diseases at the head and neck region and outside the neck region, extra-cervical lesions should be resected before approaching the head and neck PGLs. ${ }^{[6]}$ PGLs outside the head and neck region are more likely to be hormone-active. ${ }^{[6]}$

\section{Palliative Treatments}

Although surgical resection is the only curative treatment for PPGLs, surgical treatment is palliative except for resectable locoregional metastases in metastatic disease or for 
isolated distant metastases. The purpose of palliative treatment is to reduce hormone secretion and prevent metastasis-related complications in a critical anatomical location. ${ }^{[25]}$ Primary tumor resection increases overall survival in metastatic PPGLs. It also contributes positively to the improvement of symptoms in hormone-active tumors. ${ }^{[30]}$

Patients with the abdomen-limited disease are more likely to develop and maintain a postoperative biochemical response than those with the extra-abdominal disease. However, cytoreductive interventions are unlikely to cause a clinically significant persistent biochemical response. ${ }^{[30,31]}$ If curative surgical resection cannot be performed, cytoreductive surgery should be considered to decrease the volume of the target tumor tissue and increase the effectiveness of other therapeutic options, such as targeted radiotherapy. ${ }^{[6]}$ In oligometastatic PPGLs, complete metastasectomy can be considered with a patient-based approach. ${ }^{[32]}$

Wedge resection or anatomical hepatectomies may be considered to reduce tumor burden in liver metastases. Resection of metastases can help reduce symptoms related to catecholamine excess. An additional option for liver lesions is radiofrequency ablation (RFA), which can be applied peroperatively or postoperatively percutaneously. Arterial embolization and transarterial chemoembolization (TACE) have also been shown to reduce metastatic foci. ${ }^{[6]}$ Palliative options for metastatic PPGL other than cytoreductive surgery, such as RFA, cryoablation and percutaneous ethanol injection (PEI), can be effective in maintaining local control and relieving symptoms. ${ }^{[33]}$

Radiotherapy, RFA, radiosurgery (gamma knife/cyberknife) and cementoplasty are palliative treatment options in painful bone metastases. Antiresorptive treatments, such as bisphosphonate or denosumab, should be considered in bone metastases. ${ }^{[26]}$ In epidural cord compression, patients with spinal instability can benefit from a combination of spinal surgery and external radiotherapy. ${ }^{[26]}$ Before the aforementioned interventions in hormone-active metastases, patients should be stabilized cardiovascularly by treating with a-adrenergic blockade, and if necessary, $\beta$-blockers should be added. ${ }^{[26]}$ Surgery should be considered in urinary tract obstructions. ${ }^{[25]}$

\section{Systemic Treatments}

\section{Radiopharmaceuticals}

Today, 131I-MIBG therapy is the most studied treatment in metastatic PPGL and is recommended as first-line therapy in patients with positive 123I-MIBG scintigraphy and slowgrowing metastatic lesions. ${ }^{[26]}$ In a multicentric phase II study in patients with advanced PPGL, partial radiological response and stable disease were obtained in $92 \%$ of the patients with 131I-MIBG (AZEDRA, Progenics Pharmaceuticals Inc) treatment with a high specific activity. ${ }^{\left[{ }^{34]}\right.}$ Biochemical and clinical responses can be obtained with advanced somatostatin analogs, such as 90 Y-DOTATATE or $177 \mathrm{Lu}$ DOTATATE in somatostatin receptor-positive metastases in advanced PPGLs. ${ }^{[20,35]}$

\section{Systemic Chemotherapy}

Systemic chemotherapy regimens can be used to control tumor growth in fast progressive diseases. Cyclophosphamide, vincristine and dacarbazine are the standard treatment regimen in these patients. Information about signal paths and mutations in PPGL can guide targeted treatments. Targeted therapeutic agents, such as tyrosine kinase receptors associated with these signaling pathways, may be considered in therapy. ${ }^{[26]}$

\section{Follow-up}

Since all patients with PPGL have a risk of recurrence, they should be followed up after R0 resection. Existing pathological grading systems in determining whether PPGL is "malignant" or have "metastatic potential" have limited predictive strength. ${ }^{[36,37]}$ Therefore, pathologists cannot reliably identify metastatic disease from histological findings. Therefore, at least 10 years of follow-up is recommended for all patients with a history of PPGL to detect local or metastatic recurrences or new tumor formations. ${ }^{[4,5]}$ Lifelong follow-up is recommended for high-risk PCC patients (germline mutation, young age ( $<20$ years), large tumor $(>5-6 \mathrm{~cm})$, SDHB carriers) and all PGL patients. $[4,5,38]$ Of metanephrine, normetanephrine and 3-MT levels, whichever is higher preoperatively, the level of that metabolite in plasma or urine should be checked 2-6 weeks after surgery concerning the persistent disease. In patients with normal preoperative catecholamine metabolites and elevated chromogranin A levels, it is recommended to check for chromogranin A levels 2-6 weeks after surgery. ${ }^{[5]}$

In all patients who were operated due to high preoperative catecholamine values, or who were operated despite the normal catecholamine values, or patients operated without measuring catecholamine levels, control with imaging methods, and if possible, with functional imaging methods are recommended at postoperative $3^{\text {rd }}$ month. ${ }^{[5]}$

The guideline recommends performing plasma or urine metanephrine and 3-MT tests annually in patients who are under follow up. Chromogranin A test should be performed annually in patients with negative metanephrine and 3-MT tests, and positive chromogranin A. Imaging tests are recommended every 1-2 years in patients with biochemically inactive PPGL. ${ }^{[5]}$ 
To minimize radiation exposure, magnetic resonance imaging (MRI) is the preferred imaging method for follow-up, but it should be noted that it may miss tumors in unusual places. ${ }^{[32]}$ However, details of follow-up of patients who will be lifelong followed-up are uncertain, especially how often and when imaging should be performed. Accordingly, as patients are heterogeneous, a personalized follow-up program is proposed based on disease characteristics and underlying germline mutations. ${ }^{[32]}$

Clinical/biochemical control and MRI every two years are recommended for patients with high-risk mutations (especially SDHA, SDHB, SDHD (except head and neck PGLs), EPAS1 (HIF2A), PHD1/2). Computed tomography (CT) should be considered for suspected lung involvement.

For fully resected metastatic PPGL, MRI is recommended every six months, at postoperative six months and 12 months, and then annual control. CT can also be used, but since it has a radiation risk, it should be used with more caution and less frequently. An alternative approach using $\mathrm{CT}$ and $\mathrm{MRI}$ is also an option. Additional radionuclide imaging can be considered every two to three years, especially in the case of high risk mutations (SDHA/B). Functional imaging may also be considered in other risk factors.

Whole-body CT or MRI is recommended every four to six months for staging the metastatic disease. If peptide receptor radionuclide therapy is considered as the treatment option, radionuclide imaging is recommended every 1-2 years. The age of the patient and the growth rate/grade of the tumor are also important factors to be considered. ${ }^{[32]}$

\section{Postoperative Results}

PPGL increases cardiovascular morbidity and mortality. When the causes of death of patients with undiagnosed and untreated PCC were evaluated in an autopsy, it was detected that $71 \%$ of these patients died of cardiovascular causes, such as myocardial infarction, hypertensive heart failure, stroke or hemodynamic crises during unrelated interventions. ${ }^{[39]}$

In the study of Stolk et al., patients with PCC were found to have a 14-fold increased risk of cardiovascular complications such as myocardial infarction, stroke or angina pectoris, compared to patients with essential hypertension within five years before diagnosis. This is not related to differences in blood pressure or other cardiovascular risk factors, and the most likely explanation for this was stated to be the long-term exposure to toxic effects of tumoral catecholamines. ${ }^{[40]}$

In another retrospective study, $64 \%$ of patients with benign PCC had a significant reduction in blood pressure after surgery. Only one-third of the patients were shown to be drug-free normotensive. In the follow-up of these patients, life expectancy was similar in patients who did not develop metastasis compared to the paired population but lower in patients who developed metastatic disease. Therefore, lifelong follow-up for these patients is crucial concerning the metastatic disease. ${ }^{[4]]}$ In the series of Beninato et al., diabetes was detected in $23 \%$ of patients with PCC, $93 \%$ of patients had an improvement in diabetes after surgery, and $78.6 \%$ reported complete recovery. ${ }^{[42]}$

\section{Results in Cortical-Sparing Surgery}

In patients with the hereditary syndromes, such as MEN syndrome and VHL syndrome, cortex-sparing surgery, may be helpful to prevent steroid dependence. ${ }^{[20]}$

In one of the recent studies, the recurrence rate in hereditary PCC is $7 \%$, acute adrenal insufficiency is $3 \%$ in the 3 -year follow-up, and $78 \%$ of patients are steroid independent. ${ }^{[43]}$

In the median 9-year follow-up of patients with VHL syndrome who underwent cortex-sparing surgery, the metastatic disease did not develop, local recurrence was seen in $11 \%$, and $11 \%$ of patients developed PCC that required cortical-sparing surgery in the contralateral adrenal gland, and the rate of steroid-dependent patients was $11 \%{ }^{[44]}$

In patients with MEN2A who underwent cortical-sparing adrenalectomy, the contralateral adrenal recurrence rate in the 7-year follow-up was 38\%.[45]

Although there is a high risk of developing PCC in contralateral adrenal in patients with MEN syndrome, the risk of recurrence in operated adrenal is low in both VHL and MEN syndromes in patients who had cortical-sparing surgery. In the multicentric wide observational study, PCC recurrence occurred in $3 \%$ of patients undergoing cortical-sparing surgery and in $2 \%$ of patients undergoing adrenalectomy, after 6-13 years of follow-up in patients with MEN syndrome. While steroid dependence developed in $86 \%$ of patients undergoing bilateral adrenalectomy, $57 \%$ of patients undergoing bilateral cortical-sparing surgery were steroid independent. ${ }^{[46]}$ As a result, cortical-sparing surgery in selected patients can reduce the need for steroids in a significant proportion of patients.

\section{Disclosures}

Peer-review: Externally peer-reviewed.

Conflict of Interest: None declared.

Authorship Contributions: Concept - M.U., N.A.; Design - M.U., N.A.; Supervision - M.U.; Materials - M.U., N.A.; Data collection \&/or processing - M.U., N.A.; Analysis and/or interpretation - M.U.; Literature search - M.U., N.A.; Writing - M.U., N.A.; Critical review - M.U. 


\section{References}

1. Tevosian SG, Ghayee HK. Pheochromocytomas and Paragangliomas. Endocrinol Metab Clin North Am 2019;48:727-50. [CrossRef]

2. Patel D, Phay JE, Yen TWF, Dickson PV, Wang TS, Garcia R, et al. Update on Pheochromocytoma and Paraganglioma from the SSO Endocrine/Head and Neck Disease-Site Work Group. Part 1 of 2: Advances in Pathogenesis and Diagnosis of Pheochromocytoma and Paraganglioma. Ann Surg Oncol 2020;27:1329-37. [CrossRef]

3. Aygun N, Uludag M. Pheochromocytoma and Paraganglioma: From Epidemiology to Clinical Findings. Sisli Etfal Hastan Tip Bul 2020;54:159-68. [CrossRef]

4. Lenders JW, Duh QY, Eisenhofer G, Gimenez-Roqueplo AP, Grebe $\mathrm{SK}$, Murad MH, et al; Endocrine Society. Pheochromocytoma and paraganglioma: an endocrine society clinical practice guideline. J Clin Endocrinol Metab 2014;99:1915-42. [CrossRef]

5. Plouin PF, Amar L, Dekkers OM, Fassnacht M, Gimenez-Roqueplo AP, Lenders JW, et al; Guideline Working Group. European Society of Endocrinology Clinical Practice Guideline for long-term followup of patients operated on for a phaeochromocytoma or a paraganglioma. Eur J Endocrinol 2016;174:G1-10. [CrossRef]

6. Wiseman D, Lakis ME, Nilubol N. Precision Surgery for Pheochromocytomas and Paragangliomas. Horm Metab Res 2019;51:47082. [CrossRef]

7. Groeben H, Walz MK, Nottebaum BJ, Alesina PF, Greenwald A, Schumann $\mathrm{R}$, et al. International multicentre review of perioperative management and outcome for catecholamine-producing tumours. Br J Surg 2020;107:e170-8. [CrossRef]

8. Neumann HPH, Young WF Jr, Eng C. Pheochromocytoma and Paraganglioma. N Engl J Med 2019;381:552-65. [CrossRef]

9. Buitenwerf E, Osinga TE, Timmers HJLM, Lenders JWM, Feelders RA, Eekhoff EMW, et al. Efficacy of a-Blockers on Hemodynamic Control during Pheochromocytoma Resection: A Randomized Controlled Trial. J Clin Endocrinol Metab 2020;105:2381-91. [CrossRef]

10. Pacak K. Preoperative management of the pheochromocytoma patient. J Clin Endocrinol Metab 2007;92:4069-79. [CrossRef]

11. Wachtel H, Kennedy EH, Zaheer S, Bartlett EK, Fishbein L, Roses $\mathrm{RE}$, et al. Preoperative Metyrosine Improves Cardiovascular Outcomes for Patients Undergoing Surgery for Pheochromocytoma and Paraganglioma. Ann Surg Oncol 2015;22 Suppl 3:S646-54.

12. Scholten A, Cisco RM, Vriens MR, Cohen JK, Mitmaker EJ, Liu C, et al. Pheochromocytoma crisis is not a surgical emergency. J Clin Endocrinol Metab 2013;98:581-91. [CrossRef]

13. Newell KA, Prinz RA, Pickleman J, Braithwaite $S$, Brooks $M$, Karson $\mathrm{TH}$, et al. Pheochromocytoma multisystem crisis. A surgical emergency. Arch Surg 1988;123:956-9. [CrossRef]

14. Sauneuf B, Chudeau N, Champigneulle B, Bouffard C, Antona M, Pichon $\mathrm{N}$, et al. Pheochromocytoma Crisis in the ICU: A French Multicenter Cohort Study With Emphasis on Rescue Extracorporeal Membrane Oxygenation. Crit Care Med 2017;45:e657-5.

15. Takagi S, Miyazaki S, Fujii T, Daikoku S, Sutani Y, Morii I, et al. Dexa- methasone-induced cardiogenic shock rescued by percutaneous cardiopulmonary support (PCPS) in a patient with pheochromocytoma. Jpn Circ J 2000;64:785-8. [CrossRef]

16. Suh IW, Lee CW, Kim YH, Hong MK, Lee JW, Kim JJ, et al. Catastrophic catecholamine-induced cardiomyopathy mimicking acute myocardial infarction, rescued by extracorporeal membrane oxygenation (ECMO) in pheochromocytoma. J Korean Med Sci 2008;23:350-4. [CrossRef]

17. Köstek M, Aygün N, Uludağ M. Laparoscopic Approach to the Adrenal Masses: Single-Center Experience of Five Years. Sisli Etfal Hastan Tip Bul 2020;54:52-7. [CrossRef]

18. Uludağ $M$, Aygün N, İsgör A. Surgical Indications and Techniques for Adrenalectomy. Sisli Etfal Hastan Tip Bul 2020;54:8-22.

19. Uludag M, Kartal K, Aygun N. Laparoscopic adrenalectomy in a patient with situs inversus totalis. J Minim Access Surg 2017;13:602. [CrossRef]

20. Patel D, Phay JE, Yen TWF, Dickson PV, Wang TS, Garcia R, et al. Update on Pheochromocytoma and Paraganglioma from the SSO Endocrine and Head and Neck Disease Site Working Group, Part 2 of 2: Perioperative Management and Outcomes of Pheochromocytoma and Paraganglioma. Ann Surg Oncol 2020;27:1338-47.

21. Goers TA, Abdo M, Moley JF, Matthews BD, Quasebarth M, Brunt LM. Outcomes of resection of extra-adrenal pheochromocytomas/paragangliomas in the laparoscopic era: a comparison with adrenal pheochromocytoma. Surg Endosc 2013;27:428-33.

22. Patel D. Surgical approach to patients with pheochromocytoma. Gland Surg 2020;9:32-42. [CrossRef]

23. Rafat C, Zinzindohoue F, Hernigou A, Hignette C, Favier J, Tenenbaum $F$, et al. Peritoneal implantation of pheochromocytoma following tumor capsule rupture during surgery. J Clin Endocrinol Metab 2014;99:E2681-5. [CrossRef]

24. Nockel P, El Lakis M, Gaitanidis A, Yang L, Merkel R, Patel D, et al. Preoperative genetic testing in pheochromocytomas and paragangliomas influences the surgical approach and the extent of adrenal surgery. Surgery 2018;163:191-6. [CrossRef]

25. Jimenez C, Rohren E, Habra MA, Rich T, Jimenez P, Ayala-Ramirez $M$, et al. Current and future treatments for malignant pheochromocytoma and sympathetic paraganglioma. Curr Oncol Rep 2013;15:356-71.

26. Corssmit EPM, Snel M, Kapiteijn E. Malignant pheochromocytoma and paraganglioma: management options. Curr Opin Oncol 2020;32:20-6. [CrossRef]

27. Lam AK. Update on Adrenal Tumours in 2017 World Health Organization (WHO) of Endocrine Tumours. Endocr Pathol 2017;28:213-27. [CrossRef]

28. Ellis RJ, Patel D, Prodanov T, Nilubol N, Pacak K, Kebebew E. The presence of SDHB mutations should modify surgical indications for carotid body paragangliomas. Ann Surg 2014;260:158-62.

29. Robertson V, Poli F, Hobson B, Saratzis A, Ross Naylor A. A Systematic Review and Meta-Analysis of the Presentation and Surgical Management of Patients With Carotid Body Tumours. Eur J Vasc 
Endovasc Surg 2019;57:477-86. [CrossRef]

30. Roman-Gonzalez A, Zhou S, Ayala-Ramirez M, Shen C, Waguespack SG, Habra MA, et al. Impact of Surgical Resection of the Primary Tumor on Overall Survival in Patients With Metastatic Pheochromocytoma or Sympathetic Paraganglioma. Ann Surg 2018;268:172-8. [CrossRef]

31. Ellis RJ, Patel D, Prodanov T, Sadowski S, Nilubol N, Adams K, et al. Response after surgical resection of metastatic pheochromocytoma and paraganglioma: can postoperative biochemical remission be predicted? J Am Coll Surg 2013;217:489-96. [CrossRef]

32. Nölting S, Ullrich M, Pietzsch J, Ziegler CG, Eisenhofer G, Grossman A, et al. Current Management of Pheochromocytoma/Paraganglioma: A Guide for the Practicing Clinician in the Era of Precision Medicine. Cancers (Basel) 2019;11:1505. [CrossRef]

33. Kohlenberg J, Welch B, Hamidi O, Callstrom M, Morris J, Sprung $J$, et al. Efficacy and Safety of Ablative Therapy in the Treatment of Patients with Metastatic Pheochromocytoma and Paraganglioma. Cancers (Basel) 2019;11:195. [CrossRef]

34. Pryma DA, Chin BB, Noto RB, Dillon JS, Perkins S, Solnes L, et al. Efficacy and Safety of High-Specific-Activity 131I-MIBG Therapy in Patients with Advanced Pheochromocytoma or Paraganglioma. J Nucl Med 2019;60:623-30. [CrossRef]

35. Kong G, Grozinsky-Glasberg S, Hofman MS, Callahan J, Meirovitz A, Maimon O, et al. Efficacy of Peptide Receptor Radionuclide Therapy for Functional Metastatic Paraganglioma and Pheochromocytoma. J Clin Endocrinol Metab 2017;102:3278-87. [CrossRef]

36. Thompson LD. Pheochromocytoma of the Adrenal gland Scaled Score (PASS) to separate benign from malignant neoplasms: a clinicopathologic and immunophenotypic study of 100 cases. Am J Surg Pathol 2002;26:551-66. [CrossRef]

37. Kimura N, Takayanagi R, Takizawa N, Itagaki E, Katabami T, Kakoi $\mathrm{N}$, et al; Phaeochromocytoma Study Group in Japan. Pathological grading for predicting metastasis in phaeochromocytoma and paraganglioma. Endocr Relat Cancer 2014;21:405-14. [CrossRef]

38. Bausch B, Wellner U, Bausch D, Schiavi F, Barontini M, Sanso G, et al. Long-term prognosis of patients with pediatric pheochromocytoma. Endocr Relat Cancer 2013;21:17-25. [CrossRef]

39. Sutton MG, Sheps SG, Lie JT. Prevalence of clinically unsuspected pheochromocytoma. Review of a 50-year autopsy series. Mayo Clin Proc 1981;56:354-60.

40. Stolk RF, Bakx C, Mulder J, Timmers HJ, Lenders JW. Is the excess cardiovascular morbidity in pheochromocytoma related to blood pressure or to catecholamines? J Clin Endocrinol Metab 2013;98:1100-6. [CrossRef]

41. Timmers HJ, Brouwers FM, Hermus AR, Sweep FC, Verhofstad AA, Verbeek $A L$, et al. Metastases but not cardiovascular mortality reduces life expectancy following surgical resection of apparently benign pheochromocytoma. Endocr Relat Cancer 2008;15:112733. [CrossRef]

42. Beninato T, Kluijfhout WP, Drake FT, Lim J, Kwon JS, Xiong M, et al. Resection of Pheochromocytoma Improves Diabetes Mellitus in the Majority of Patients. Ann Surg Oncol 2017;24:1208-13. [CrossRef]

43. Grubbs EG, Rich TA, Ng C, Bhosale PR, Jimenez C, Evans DB, et al. Long-term outcomes of surgical treatment for hereditary pheochromocytoma. J Am Coll Surg 2013;216:280-9. [CrossRef]

44. Benhammou JN, Boris RS, Pacak K, Pinto PA, Linehan WM, Bratslavsky $\mathrm{G}$. Functional and oncologic outcomes of partial adrenalectomy for pheochromocytoma in patients with von Hippel-Lindau syndrome after at least 5 years of followup. J Urol 2010;184:1855-9. [CrossRef]

45. Asari R, Scheuba C, Kaczirek K, Niederle B. Estimated risk of pheochromocytoma recurrence after adrenal-sparing surgery in patients with multiple endocrine neoplasia type 2A. Arch Surg 2006;141:1199-205. [CrossRef]

46. Castinetti F, Qi XP, Walz MK, Maia AL, Sansó G, Peczkowska M, et al. Outcomes of adrenal-sparing surgery or total adrenalectomy in phaeochromocytoma associated with multiple endocrine neoplasia type 2: an international retrospective population-based study. Lancet Oncol 2014;15:648-55. [CrossRef] 